\title{
Influenza virus surveillance among young children in São Paulo, Brazil: The impact of vaccination
}

\author{
Tatiane Karen Cabeça, Aripuanã Watanabe, Luciana Peniche Moreira, Thaís Boim \\ Melchior, Ana Helena Perosa, Clarice Camargo, Sheila Negrini Parmezan, Nancy Bellei \\ Laboratório de Virologia Clínica, Disciplina de Infectologia, Departamento de Medicina, Universidade \\ Federal de São Paulo, São Paulo, Brazil.
}

Submitted: June 11, 2013; Approved: March 14, 2014.

\begin{abstract}
This study assessed the presence of influenza virus among young children and the coverage of vaccination from 2010 to 2012 in São Paulo, Brazil. Our results demonstrated a lower rate of influenza detection and a predominance of influenza B. A decrease of coverage vaccination through the surveillance periods was observed.
\end{abstract}

Key words: influenza virus, surveillance, vaccination.

Young children have the immune response less robust than in older children against influenza infection. In community studies, school-aged children have had the highest rates of infection and disease. Prospective surveillance studies of influenza illness in preschool- and school-aged children demonstrate that annually, between $15 \%$ and $42 \%$ of children are infected (Glezen and Couch, 1978; Neuzil et al., 2002).

Infected children shed infectious virus for longer periods and at higher titers than adults do, which may explain in part why children in child care and school play a central role in the spread of virus in a community (Rennels and Meissner, 2002).

Influenza infection has been associated with complications such as exacerbations of wheezing and asthma, increased airway hyper-reactivity and hospitalization. Only recently has it become fully appreciated that the risk of influenza-associated hospitalization for healthy young children is similar to that for previously recognized high-risk groups. They also appear to be at higher risk of hospitalization from influenza than are healthy 50 - to 64-year-olds, for whom routine immunization has been recommended since 2000 (Barker and Mullooly, 1980; Izurieta et al., 2000; Neuzil et al., 2000a; Neuzil et al., 2000b; Simonsen et al., 2000; Neuzil et al., 2002).

The circulating influenza virus strains and their match to vaccine strains and the timing and severity of the influ- enza season vary annually. The current influenza vaccine formulation contains 3 virus strains: $\mathrm{A}(\mathrm{H} 1 \mathrm{~N} 1), \mathrm{A}(\mathrm{H} 3 \mathrm{~N} 2)$, and only a B strain.

Most guidelines support the opinion that influenza vaccination should be given to patients with asthma, including children (Nicholson et al., 1995). The proportion of children with asthma that is vaccinated varies widely and is lower than in the older population (Kramarz et al., 2000).

The assessment of the disease burden over multiple years, mainly on post-pandemic years, is needed to estimate the impact of strategies of prevention on the burden of influenza viruses beyond of determine the circulation pattern of these viruses.

The goal of our study was to assess the presence of influenza virus among symptomatic young children presenting wheezing as well as the coverage of influenza vaccination from 2010 to 2012 in a region from the South hemisphere.

Symptomatic children attended at an emergency room of São Paulo Federal University/São Paulo University Hospital during the influenza season, with acute respiratory infection of probable viral etiology were enrolled by a pediatrician after the consent form was signed by the parents or guardians. The inclusion criterion was: children aged $\leq 5$ years old presenting fever and wheezing up to 7 days. The Ethics Committee of São Paulo Federal University (CEP 0421/10) approved this study. Overall, 74 naso-

Send correspondence to N. Bellei. Laboratory of Clinical Virology, Discipline of Infectology, Department of Medicine, Federal University of São Paulo, Rua Pedro de Toledo 781, $15^{\text {th }}$ floor, 04039-032 Vila Clementino, São Paulo, SP, Brazil. E-mail: nbellei@uol.com.br. 
pharyngeal swabs samples were collected. Nucleic acid was extracted from $140 \mu \mathrm{L}$ of collected samples using the QIAmp Viral RNA Extraction kit (Qiagen, Germany), according to the manufacturer's recommendations. For detection influenza A (seasonal and pandemic) and influenza B, we performed the CDC Real-time PCR protocol for influenza A (H1N1) pdm09 (CDC, 2009) with minor modifications. Primers used for detection of influenza B targeting the NS gene segment (Selvaraju and Selvarangan 2010); RnaseP was used as internal control. A total volume of $25 \mu \mathrm{L}$ was used for each reaction, containing $5 \mu \mathrm{L}$ of RNA extracted, $0.8 \mu \mathrm{M}$ primer, $0.2 \mu \mathrm{M}$ probe, $1 \mathrm{x}$ RT-PCR Enzyme Mix, 1x RT-PCR Buffer with AgPath-ID ${ }^{\mathrm{TM}}$ One Step RT-PCR (Ambion, EUA) and Influenza A 2009 H1N1 Assay Set v1.0 (Applied Biosystems, EUA) on a model ABI 7500 real-time. The reaction occurred under the following conditions: $50{ }^{\circ} \mathrm{C}$ for $30 \mathrm{~min}, 95^{\circ} \mathrm{C}$ for $10 \mathrm{~min}$ and $45 \mathrm{cy}$ cles of $95^{\circ} \mathrm{C}$ for $15 \mathrm{~s}$ and $55^{\circ} \mathrm{C}$ for $30 \mathrm{~s}$.

The average age of the patients included in the study was 1 year old (range from 1 month to 5 years old). Out of 74 clinical samples enrolled in the study, 4 (5.4\%) were positive for influenza virus. All the 4 positive cases were identified as influenza $B$ virus and no influenza A detection was found. The positive cases of influenza $B$ infection were registered only during 2011. Considering the total of patients who were included in the study during 2011, the influenza B infection rate was $10.2 \%(4 / 39)$.

The average age of influenza positive cases was 1.5 year old. Cough and coryza were the most common clinical presentations of infected cases. Sore throat and diarrhea were more reported among the influenza B positive cases than the negative ones, with $50 \%$ and $25 \%$ respectively. The influenza coverage vaccination rate among the 74 investigated subjects was $57.1 \%$. Four out of 74 included cases had no vaccination information. There was a decrease on the vaccination rate through the surveillance period, which 2010 was the year with the largest influenza vaccination coverage. The Table 1 shows the distribution of coverage vaccination on the surveillance years of the study.

On the 4 influenza B identified cases, two had received the influenza vaccine during the years 2010 and 2011.

The Advisory Committee on Immunization Practices (ACIP) of the Centers for Disease Control and Prevention (CDC) recommends routine vaccination of children 6-23 months of age and has extended the recommendation to children up to 5 years of age (Harper et al., 2005).

Our results showed a low rate of influenza positive cases among children presenting fever and wheezing. This data was probably influenced by a good rate of influenza coverage vaccination, even among unvaccinated children, once it should be considered the indirect herd effect from vaccination, a phenomenon that offers potential for improving the effectiveness of influenza prevention in the remaining unvaccinated population.
Table 1 - Influenza coverage vaccination on the surveillance years.

\begin{tabular}{ccc}
\hline Year & Vaccination rate* & No information \\
\hline 2010 & $80 \%$ & 0 \\
2011 & $65.8 \%$ & 1 \\
2012 & $40.7 \%$ & 3 \\
\hline
\end{tabular}

Studies have shown a major rate of influenza virus detection among children aged up 5 years old than preschool aged children (Wu et al., 2010; Raboni et al., 2011). Since influenza infection can lead to lower respiratory tract infection and hospitalization, mainly on some risk group patients, such as children presenting wheezing, the vaccination can play an important role on influenza infection prevention and control among preschool- and school-aged children.

The first period of our study revealed a higher rate of influenza coverage vaccination decreasing through the next seasons. Due to the influenza A (H1N1) pandemic in 2009, there was a higher coverage of vaccination in 2010. However, during the post-pandemic influenza pandemic the vaccine adherence decreased. The significant reduction on influenza A (H1N1) pdm09 infection cases during 2010 may be related with a major concern due to the impact that the first pandemic influenza wave (2009) played worldwide. On the other hand, the inclusion of children aged up 2 years old in the Brazilian annual vaccination program on influenza virus is recent. In this regard, the knowledge on influenza virus season impact as well as the need of an annual revaccination is not truly understood among the medical and non-medical community.

Our surveillance data showed influenza B detection only in 2011 and we hypothesized that the post-pandemic influenza wave may be influenced dynamic of influenza different strains circulation.

In our study, we found two influenza B detections on children who were vaccinated against influenza virus. However, these two cases were not considered to be immunized against influenza once they had been recently vaccinated and protective antibody titers are usually achieved after two weeks of vaccination. In addition, the 2011-12 trivalent influenza vaccine contains a strain of influenza B/Victoria-lineage viruses. Recently a study carried out on Taiwan revealed a predomination by influenza B/Yamagata-lineage viruses occurred during the 2011-12 season (Lo et al., 2013). Although our study was not directed to investigate the linage viruses on influenza positive cases, the possibility of influenza B/Yamagata-lineage viruses should be considered. In this regard, introducing a quadrivalent influenza vaccine that includes strains of both B lineages may improve influenza control among young children.

The low incidence of influenza-infected cases observed in the surveillance period may be considered a limitation of our study. 
In conclusion, our study showed the impact of vaccination on influenza virus circulation among young children during 2010-2012 with a lower rate of influenza detection. The decrease of vaccination coverage through the surveillance periods supports the need to maintain programs to stimulate vaccine adherence on children.

\section{Acknowledgments} teur.

This work was supported by a grant from Sanofi Pas-

\section{References}

Barker WH, Mullooly JP (1980) Impact of epidemic type A influenza in a defined adult population. Am $\mathrm{J}$ Epidemiol 112:798-811.

Centers for Disease Control and Prevention [on line] 2009 CDC protocol of realtime RT-PCR for influenza A (H1N1). Available at: http://www.who.int/csr/resources/publications/swineflu/CDCRealtimeRTPCR_SwineH1Assay-2009 _20090430.pdf. Accessed 26 May 2013.

Glezen WP, Couch RB (1978) Interpandemic influenza in the Houston area. N Engl J Med. 298:587-592.

Harper SA, Fukuda K, Uyeki TM, Cox NJ, Bridges CB (2005) Prevention and control of influenza. Recommendations of the Advisory Committee on Immunization Practices (ACIP). MMWR Morb Mortal Wkly Rep 54 RR08:1-40.

Izurieta HS, Thompson WW, Kramarz P, Shay DK, Davis RL, DeStefano F, Black S, Shinefield H, Fukuda K (2000) Influenza and the rates of hospitalization for respiratory disease among infants and young children. $\mathrm{N}$ Engl J Med 342:232-239.

Kramarz P, DeStefano F, Gargiullo PM, Davis RL, Chen RT, Mullooly JP, Black SB, Bohlke K, Ward JI, Marcy MS, Okoro CA (2000) Influenza vaccination in children with asthma in health maintenance organizations: Vaccine Safety Datalink Team. Vaccine 18:2288-2294.

Lo YC, Chuang JH, Kuo HW, Huang WT, Hsu YF, Liu MT, Chen $\mathrm{CH}$, Huang HH, Chang CH, Chou JH, Chang FY, Lin TY,
Chiu WT (2013) Surveillance and vaccine effectiveness of an influenza epidemic predominated by vaccinemismatched influenza B/Yamagata-lineage viruses in Taiwan, 2011-12 season. PLoS One 8(3):e58222.

Neuzil KM, Mellen BG, Wright PF, Mitchel EF Jr, Griffin MR (2000a) The effect of influenza on hospitalizations, outpatient visits, and courses of antibiotics in children. N Engl J Med 342:225-231.

Neuzil KM, Wright PF, Mitchel EF Jr, Griffin MR (2000b) The burden of influenza illness in children with asthma and other chronic medical conditions. J Pediatr 137:856-864.

Neuzil KM, Zhu Y, Griffen MR, Edwards KM, Thompson JM, Tollefson SJ, Wright PF (2002) Burden of interpandemic influenza in children younger than 5 years: a 25 -year prospective study. J Infect Dis 85:147-152.

Nicholson KG, Snacken R, Palache AM (1995) Influenza immunization policies in Europe and the United States. Vaccine 13:365-369.

Raboni SM, Stella V, Cruz CR, França JB, Moreira S, Gonçalves L, Nogueira MB, Vidal LR, Almeida SM, Debur MC, Carraro H Jr, dos Santos CN (2011) Laboratory Diagnosis, Epidemiology, and Clinical Outcomes of Pandemic Influenza A and Community Respiratory Viral Infections in Southern Brazil. J Clin Microbiol 49:1287-1293.

Rennels MB, Meissner HC and Committee on Infectious Diseases 2002 Technical Report: Reduction of the Influenza Burden in Children. Pediatrics 110:e80.

Selvaraju SB and Selvarangan R (2010) Evaluation of three influenza $A$ and $B$ real-time reverse transcription-PCR assays and a new 2009 H1N1 assay for detection of influenza viruses. J Clin Microbiol 48(11):3870.

Simonsen L, Fukuda K, Schoenberger LB, Cox NJ (2000) The impact of influenza epidemics on hospitalizations. J Infect Dis 181:831-837.

Wu JT, Ma ES, Lee CK, Chu DK, Ho PL, Shen AL, et al. Cowling BJ, Malik Peiris JS (2010) The infection attack rate and severity of 2009 pandemic H1N1 influenza in Hong Kong. Clin Infect Dis 51:1184-1191.

All the content of the journal, except where otherwise noted, is licensed under a Creative Commons License CC BY-NC. 